\title{
85642 - GERONTOTECNOLOGIA EDUCACIONAL PARA PROMOÇÃO DA SAÚDE DE IDOSOS EM TRATAMENTO HEMODILIATICO
}

\author{
Pôster - Gerontologia
}

\author{
Anderson Abreu de Carvalho / Carvalho, AC / Universidade Federal de Santa Catarina; \\ Naísa Falcão Martins / Martins, NF / Universidade Federal de Santa Catarina; \\ Karina Silveira de Almeida Hammerschmdt / Hammerschmdt, KSA / Universidade Federal de Santa Catarina; \\ Juliete Coelho Gelsleuchter / Gelsleuchter, JC / Universidade Federal de Santa Catarina; \\ Juliana Balbinote Reis Girondi / Gironde, JBR / Universidade Federal de Santa Catarina; \\ Gustavo Lopes Soares / Soares, GL / Universidade Federal de Santa Catarina
}

Introdução: Com crescimento da população idosa, aumenta a incidência de doenças crônicas como a doença renal crônica1. A hemodiálise é tratamento mais utilizado e interfere diretamente sobre qualidade de vida2. Para tanto as gerontotecnologias educacionais podem ser capazes de envolver o indivíduo no autocuidado3. Objetivo: Promover a saúde dos idosos em tratamento hemodialítico, através da aplicação de gerontotecnologia educacional. Metodologia: Pesquisa Convergente Assistencial. Participaram idosos a partir dos 60 anos, que realizavam hemodiálise, num hospital universitário do Sul do país. Para coleta de dados utilizou-se de entrevista semiestruturada para levantamento de dados característicos. Posteriormente, foram elencadas categorias, para identificação de temas a serem abordados em posterior aplicação da gerontotecnologia "Jogo das Atitudes". Realizou-se entre novembro de 2017 e fevereiro de 2018. Número do CEP: 1.097.377. Resultados: Participaram 12 idosos. Referente auto percepção, emergiu as categorias: Prevenção, Cronicidade, Conhecimento, Déficit de atividades, Empoderamento. A aplicação da gerontotecnologia se deu a partir da avaliação comparativa das categorias. Trata-se de jogo de cartas com atitudes positivas (cartas verdes) e negativas (vermelhas) e um dado com as cores verde evermelho. O objetivo é a reflexão das atitudes e ganha quem teve mais atitudes positivas. A cada leitura das cartas, os participantes faziam autoavaliação de suas atitudes e se orgulhavam de alguma tarefa que faziam corretamente. Após a aplicação do jogo identificou-se categorias: Empoderamento, Conhecimento, Superação, Ocupação. Conclusão: Promoveu-se reflexão do paciente no seu tratamento, firma-se resultante a promoção á saúde, bem como tributos que levam a uma melhora na autopercepção de saúde desses idosos em tratamento hemodialítico.

Palavras-chave: Idoso; Insuficiência Renal Crônica; Diálise; Tecnologia educativa.

Referências: 1. IBGE. Queda substancial do tamanho da família, nas duas últimas décadas. 2015. Disponível em: https://teen.ibge.gov.br/sobreobrasil/populacoa/nupcialidadeefecundidade.html; 2. DRESCH, Flavia Kirsch et al. ondição de saúde auto percebida e prevalência de doenças crônicas não transmissíveis em idosos atendidos pela estratégia da saúde da família. Revista Conhecimento Online, v. 2, p. 118-127, 2017; 3. HAMMERSCHMIDT, Karina Silveira de Almeida et al. Cuidado de Enfermagem: Interfaces teóricas e práticas no ciclo vital do ser humano. Curitiba: Crv, 2015. 